\title{
Burden of tobacco, kola nut and alcohol consumption and its association with periodontal disease, potentially malignant lesions and quality of life among bus drivers, Lagos State, Nigeria
}

\author{
Afolabi Oyapero ${ }^{1}$, Oyejoke Oyapero ${ }^{2}$, Aliru I. Akinleye ${ }^{3}$
}

\section{AFFILIATION}

1 Lagos State University College of Medicine, Ikeja, Nigeria

2 Department of Paediatrics, Amuwo Odofin Maternal and Child Centre, Festac, Nigeria

3 Department of Oral Pathology and Oral Medicine, Lagos State University Teaching Hospital, Ikeja, Nigeria

\section{CORRESPONDENCE TO}

Afolabi Oyapero. Lagos State University College of Medicine, 1-5 Oba Akinjobi Way, Ikeja, Lagos, Nigeria. E-mail: fola_ba@yahoo.com

Popul. Med. 2020;2(March):5

\section{KEYWORDS}

quality of life, tobacco, periodontal disease, potentially malignant lesions, bus drivers

Received: 10 January 2020, Revised: 3 February 2020, Accepted: 3 March 2020

https://doi.org/10.18332/popmed/118726

\begin{abstract}
INTRODUCTION To improve their performance and alertness, bus drivers are known to abuse alcohol, cigarette, kola nut and other substances that have substantial independent and combined deleterious effects on oral tissues. The study aimed to characterize risk associations between aggregates of alcohol/tobacco use and oral-health outcomes among a group of road transport workers in the Ojota and Berger bus terminals in Lagos State.

METHODS Data were obtained from a probability sample of 150 commercial drivers from two bus terminals (Ojota and Berger) in Lagos State via face-to-face interviews and oral examination using a validated structured questionnaire. Multistage cluster sampling was conducted through the selection of two clusters from the major registered motor parks at the first stage by simple random sampling; while the selection of drivers was done by simple random sampling (balloting), using the list of registered drivers in the two garages as the sampling frame. Past and present tobacco and alcohol use were self-reported by respondents. Multivariable regression analysis measured the relationship between the outcomes [potentially malignant lesions (Leukoplakia, Erythroplakia, Smokers palate, Lichen planus), periodontal disease (CPITN Scores 3,4) and oral-health-related quality of life, OHRQoL (OHIP-14)] and exposures, controlling for the covariates age, marital status, education status, income
\end{abstract}

level, oral hygiene, dental caries, functional tooth units, and previous treatment.

RESULTS All the respondents were male. The prevalence of alcohol ever use was $82 \%$, and $35 \%$ were moderate or heavy drinkers (2-4 drinks). Prevalence of tobacco ever use was $71 \%$; while $32 \%$ were heavy smokers ( $>11$ cigarettes/ day), $64 \%$ had a history of kola nut chewing habit, and $53 \%$ ate at least 2 kola nuts daily. Heavy smokers had more potentially malignant lesions (OR=1.89, 95\% CI: 1.33-3.27); significantly worse periodontal destruction $(\mathrm{OR}=3.12,95 \%$ CI: 2.28-5.17); and significantly worse OHRQoL (OR=2.35, 95\% CI: 1.42-4.54). For individual OHRQoL domains, Pain 3.03 ( 95\% CI: 1.77-4.21], Discomfort 2.89 [ 95\% CI: 2.324.17], Speech 3.02 ( 95\% CI: 2.32-4.13), Diet 2.77 (95\% CI: 1.87-4.28), Embarrassment 1.97 (95\% CI: 1.65-3.14) and Self-consciousness 2.34 (95\% CI: 1.93-3.48), were significantly associated with heavy smoking, after controlling for covariates.

CONCLUSIONS This study highlights the role of tobacco and alcohol as modifiable risk factors for periodontal disease and potentially malignant lesions that can impact negatively on OHRQoL. Bus drivers, in Lagos State, Nigeria, are an important target group in controlling tobacco and alcohol use in Nigeria and should receive adequate attention for oral health promotion and other preventive initiatives. 


\section{INTRODUCTION}

Occupation has a direct bearing on health, wellbeing, and quality of life, while several psychosocial and physical risk exposures make workers in agricultural, construction, healthcare and transportation occupations especially prone to health disparities ${ }^{1}$. Personnel in the transportation sector often experience inadequate rest and have sleep deprivation due to long working hours, in addition to being deprived of home and other support systems ${ }^{2}$. Additionally, they are predisposed to risky behaviors and lifestyles such as alcohol consumption and casual sex ${ }^{3}$, placing them at high risk for sexually transmitted infections (STIs), HIV, and hepatitis virus transmission ${ }^{4}$. These drivers often abuse psychoactive substances such as marijuana, cocaine, amphetamines, and cigarettes, to reduce sleepiness during trips, endure stress and to improve socialization, among other reasons $\mathrm{s}^{5,6}$. A recent study obtained a prevalence as high as $82.9 \%$ for cigarette smoking among bus, minibus and taxi drivers ${ }^{7}$.

Many of the substances abused by bus drivers have grave consequences on general and oral health. Marijuana abuse causes acidic erosion from cannabinoid hyperemesis, dental caries, gingival inflammation, leukoplakia, oral papilloma and tongue carcinoma ${ }^{8}$. Several epidemiological studies have also confirmed a strong association between tobacco use and periodontal disease ${ }^{9}$. Smokers typically have more severe periodontal destruction, attachment loss, and pocket formation, with an established dose-response relationship between the numbers of cigarettes smoked daily and the odds of periodontal disease ${ }^{10}$. Alcohol similarly increases the risk of developing periodontal disease ${ }^{11}$, due to decreased resistance to infection by Gram-negative organisms during acute alcohol intoxication ${ }^{12}$. Research has shown a positive correlation between gamma glutamyl transpeptidase, a liver enzyme and an indicator of alcohol consumption and periodontal attachment loss ${ }^{13}$.

Furthermore, a strong association between oropharyngeal cancer and tobacco use is widely documented. Epidemiological evidence shows that the odds ratio can be as high as $\mathbf{1 7}$ times higher for extremely heavy smokers who smoke 80 or more cigarettes per day ${ }^{14}$. Alcohol, in addition, acts additively and even synergistically with tobacco in the pathogenesis of cancers ${ }^{15}$. Most oral squamous cell carcinomas arise from premalignant precursor lesions ${ }^{16}$ and alcohol has been found to increase the risk of oral premalignant lesion (OPL) in the presence of tobacco. After adjustment for tobacco use, some analytical studies observed an odds ratio of 2 to 3 for leukoplakia, oral submucous fibrosis, erythroplakia, and oral epithelial dysplasia ${ }^{17,18}$.

The oral diseases caused by tobacco and alcohol use, such as oral cancer, periodontal disease, tooth loss, oral malodor, dental caries and teeth staining, have significant impacts on physical, psychological and social well-being, and oral-healthrelated quality of life (OHRQoL) $)^{19,20}$. Maida et al. ${ }^{21}$ observed worse OHRQoL among current smokers while Åstrøm et al. ${ }^{22}$ observed a correlation between the duration of smoking and
OHRQoL. Since commercial bus drivers are known to indulge in these deleterious oral habits, the present study aimed to determine the association between tobacco, alcohol and kola nut consumption and the prevalence of periodontal disease and potentially malignant lesions, as well as association with quality of life in this high risk group in Lagos State, Nigeria.

\section{METHODS}

\section{Study setting and population}

This was a motor park based descriptive study conducted among bus drivers at the Ojota and Berger bus terminals in Lagos State, Nigeria. Lagos State has a population of over 17 million people in 20 local government areas (LGAs), 37 local council development areas consisting of approximately 2000 communities $^{23}$. The participants were bus drivers who operate the public intra-city and inter-city transport services in the metropolis. A multistage cluster sampling method was used to recruit drivers among those registered with the National Union of Road Transport Workers (NURTW) and Road Transport Employers Association of Nigeria (RTEAN). The first stage involved selection of two clusters by simple random sampling from the list of the major registered motor parks that serve as a connecting nucleus to major cities in Lagos State and other Southwestern states in Nigeria with a sizeable number of drivers. The second stage involved the random selection of drivers and bus conductors that were on the list of registered transporters that were in the two bus stations, by simple random sampling (balloting), using the list of registered drivers in the two garages as the sampling frame. Bus drivers employed for at least 3 years prior to the study, were above 18 years old, and who gave informed consent, were enlisted. Those excluded from the study included those with diabetes mellitus or hypertensive patients on calcium channel blockers, which can worsen periodontal inflammation.

The primary outcome was periodontal disease, while $80 \%$ power and a confidence interval of $95 \%$ and an absolute precision of 0.05 were adopted. Since we were not comparing two groups, and our study design is descriptive and not experimental, we calculated the sample size from:

\section{$n=z^{2} p(1-p) / d^{2}$}

where, $n=$ required sample size, $z=$ confidence level at 95\% (standard value of 1.96), $p=$ expected prevalence or proportion of chronic gingivitis in the project area, and $d=$ precision or margin of error at 5\% (standard value of 0.05 ). Using a prevalence of $8 \%$ for severe periodontal attachment loss among tobacco smokers from a reference study ${ }^{24}$, a sample size of 150 was determined.

Ethical approval to conduct this study was obtained from the Health Research and Ethics Committee of the Lagos State University Teaching Hospital (LREC/06/10/1177). Verbal permission was obtained from the Road Transport Employers Association of Nigeria (RTEAN) and NURTW 
executive at each park, while individual written consent was obtained from each participating driver.

The study was conducted from 14 January to 21 June 2019. Respondents were recruited between January and March while data analysis was done in April and May. We used an adapted validated interviewer-administered questionnaire to obtain the data. It was pretested for face and content validity by three experts in oral pathology, community dentistry, and periodontology, who gave their expert opinion with regard to its relevance and straightforwardness and tested the content validity. The English language questionnaire was translated into Yoruba language by two bilingual experts in English and Yoruba by a forward and backward translation method. Furthermore, a pilot test was performed on a random sample of 25 drivers from Yaba garage to test the reliability of the questionnaire. Amendments were made to the questionnaire without altering the meaning of relevant terms. Questionnaire reliability coefficient, obtained by calculating Cronbach's alpha, was found to be adequate (0.83).

The questionnaire included sections on sociodemographic characteristics, OHRQoL, health-related behavior such as cigarette smoking, alcohol consumption and kola nut chewing as well as a section on oral examination. Ever smokers were classified as those who had previously smoked cigarettes (smoked at least 100 cigarettes in their lifetime or at least 1 cigarette/day for one year), while never smokers were those who had never smoked a cigarette. Former smokers were classified as those who had smoked $>100$ cigarettes in their lifetime but had not smoked in the last one month. Cigarette smokers were categorized into light (1-5 cigarettes/day), moderate (6-10 cigarettes/day) or heavy smokers ( $\geq 11$ cigarettes/day). OHRQoL was determined using the Oral Health Impact Profile (OHIP-14), a shortened version of OHIP-49 developed using a conceptual model of oral health by Locker ${ }^{25}$. The questionnaire has 14 items of impact (subdomains), which are conceptually grouped into seven domains: functional limitation, physical pain, psychological discomfort, physical disability, psychological disability, social disability and handicap. To calculate the OHIP-14 impact scores for individual subdomains, the mean of the subjects' scores was obtained to give a maximum score of 4 . For individual subdomain scores, 0,1 and 2 were classified as low impact while scores 3 and 4 were classified as high impact.

Moderate alcohol consumption was defined as taking up to 14 units of alcohol weekly while heavy drinking was defined as taking 2-4 drinks daily or more than 15 units weekly. A former alcohol drinker was classified as a previous drinker who has had no drinks in the past year. Occasional kola nut consumption was defined as taking 1-2 nuts weekly while daily kola nut consumption was defined as taking 1-2 nuts daily. A former kola nut consumer was classified a previous consumer who had not chewed a kola nut in the past year.
Oral examination was done using the criteria established by $\mathrm{WHO}^{26}$. Periodontal measurements were determined using the following continuous measures: clinical attachment loss (CAL), probing pocket depth (PPD), and gingival Index (GI). Leukoplakia was defined as a white patch or plaque that does not rub off and cannot be characterized clinically as any other disease, while Erythroplakia as a red patch that cannot be clinically diagnosed as any other condition. Erythroleukoplakia was characterized as an area of leukoplakia that has red patches, while lichen planus was identified as a dermatologic lesion with mucosal involvement with a reticular or erosive pattern. The principal investigator, who had been assessed by a consultant oral pathologist with an intra-examiner kappa score of 0.92 conducted all clinical examinations while a trained research assistant recorded the findings. Examinations were conducted using standard precautions with gloved hands, mouth mirrors and periodontal probes in a well-lit environment. Visual examination, digital palpation of the mucosa, and periodontal examination using Williams periodontal probes, were done and findings were appropriately recorded.

\section{Data processing and analysis}

The data were analyzed using the Statistical Package for Social Sciences (SPSS) version 22.0 (IBM, Armonk, NY). Categorical variables are given as frequencies and percentages, while continuous variables as mean \pm standard deviation. For the OHIP-14, scores were converted from ordinal to scale values and divided into low, moderate and high impacts. The total impact score was also calculated by adding up the individual scores recorded for the 14 items. For the bivariate analyses, chi-squared tests were used to test for statistical significance. Additionally, Fisher's exact test was used to examine the association of the outcome variable with categorical independent variables when the sample size was relatively small. An ordinal logistic regression analysis was performed to determine odds ratios and confidence intervals. The main predictor variable was smoking status while the main outcome was periodontal disease. We controlled for other variables such as alcohol consumption, kola nut chewing and sociodemographic variables, and also measured other outcomes (potentially malignant lesions and OHRQoL). Two-tailed p-values $<0.05$ and $95 \% \mathrm{CI}$ were considered to be statistically significant.

\section{RESULTS}

The sample of 150 male respondents comprised mainly those aged 30-49 years (73.7\%) who had high school level education or less (70.9\%). Prevalence for ever use of cigarettes, alcohol and kola nut was $71 \%, 82 \%$ and $64 \%$, respectively. Bivariate analyses using chi-squared or Fisher's exact test revealed significant associations between income, educational attainment, smoking, alcohol consumption, kola nut consumption, and age group. Respondents aged 30-49 years were significantly more likely to be heavy smokers, 
heavy alcohol drinkers, and daily kola nut consumers $(\mathrm{p}<0.005)$ (Table 1).

Table 2 gives a summary of the periodontal parameters of the respondents based on their pattern of tobacco smoking. The prevalence of gingivitis was insignificantly higher among light smokers while the prevalence of moderate/severe periodontitis was significantly higher among heavy smokers $(p<0.05)$. Heavy smokers similarly had significantly higher percentage of sites with probing depth $>4 \mathrm{~mm}$ [35.7 (3.8)] and mean CAL [5.3 (0.9)] $(\mathrm{p}<0.05)$. Nicotinic stomatitis and leukoplakia were similarly significantly prevalent among heavy smokers $(\mathrm{p}<0.001)$ while they also had more erythroplakia, lichen planus, non-healing ulcers and indeterminate lesions.

Bivariate analyses between proportions with severe impacts in OHRQoL subdomains and participant characteristics are presented in Table 3. Respondents aged 30-49 years, those with high school education or less, heavy smokers, heavy alcohol drinkers, and daily kola nut consumers, had more severe impacts in the subdomains of pain, discomfort, difficulty speaking, chewing, social embarrassment and self-consciousness.

Table 1. Association between age and other sociodemographic/clinical characteristics of participants ( $\mathrm{N}=150)$

\begin{tabular}{|c|c|c|c|c|c|}
\hline \multirow{3}{*}{ Characteristics } & \multirow{3}{*}{$\begin{array}{c}\text { Overall } \\
\text { \% }\end{array}$} & \multicolumn{3}{|c|}{ Age (years) } & \multirow[b]{3}{*}{$\mathbf{p}^{\mathrm{a} *}$} \\
\hline & & 18-29 & $30-49$ & $\geq \mathbf{5 0}$ & \\
\hline & & $\%$ & $\%$ & $\%$ & \\
\hline Population & 100 & 9.8 & 73.7 & 16.5 & \\
\hline \multicolumn{6}{|l|}{ Monthly income (NGN)** } \\
\hline$<20000$ & 5.3 & 3.7 & 1.6 & 0.0 & 0.035 \\
\hline $20000-50000$ & 15.3 & 1.6 & 9.5 & 4.2 & \\
\hline 51000-100000 & 41.3 & 1.1 & 34.4 & 5.8 & \\
\hline$>100000$ & 19.6 & 1.1 & 14.8 & 3.7 & \\
\hline Chose not to answer & 18.5 & 2.1 & 14.8 & 1.6 & \\
\hline \multicolumn{6}{|l|}{ Education } \\
\hline High school education or less & 70.9 & 4.6 & 53.2 & 42.2 & 0.039 \\
\hline Post high school diploma/certificate & 21.9 & 2.6 & 16.1 & 3.2 & \\
\hline University degree & 7.2 & 2.6 & 4.6 & 0.0 & \\
\hline \multicolumn{6}{|l|}{ Number of household members } \\
\hline $1-3$ & 19.2 & 50.0 & 30.0 & 20.7 & 0.000 \\
\hline $3-6$ & 39.2 & 29.4 & 32.1 & 27.5 & \\
\hline$>6$ & 31.6 & 20.2 & 37.6 & 50.8 & \\
\hline \multicolumn{6}{|l|}{ Payment for healthcare } \\
\hline Some form of insurance & 7.5 & 3.7 & 2.7 & 1.1 & 0.000 \\
\hline Out of pocket & 93.0 & 6.5 & 71.5 & 15.0 & \\
\hline \multicolumn{6}{|l|}{ Smoking status } \\
\hline Never & 29.0 & 7.0 & 10.0 & 12.0 & 0.007 \\
\hline Stopped & 4.0 & 2.1 & 0.5 & 1.4 & \\
\hline Light & 35.0 & 2.0 & 25.9 & 7.1 & \\
\hline Heavy & 32.0 & 0.0 & 23.4 & 8.6 & \\
\hline \multicolumn{6}{|l|}{ Alcohol drinking } \\
\hline Never & 18.0 & 5.2 & 11.2 & 1.6 & 0.003 \\
\hline Stopped & 0.0 & 0.0 & 0.0 & 0.0 & \\
\hline Light & 47.0 & 2.6 & 32.9 & 11.5 & \\
\hline Heavy & 35.0 & 1.6 & 24.5 & 8.9 & \\
\hline \multicolumn{6}{|l|}{ Kola nut consumption } \\
\hline Never & 36.0 & 22.0 & 12.0 & 0.0 & 0.003 \\
\hline Occasional & 11.0 & 1.1 & 8.1 & 1.8 & \\
\hline Daily & 53.0 & 3.5 & 37.7 & 11.8 & \\
\hline
\end{tabular}

* All p-values significant. a p-value based on chi-squared test, Fisher's exact test for cells <5. ** NGN: 361 Nigerian Naira about 1 US\$ in 2019. 
Table 2. Periodontal parameters and potentially malignant lesions observed among participants according to smoking status

\begin{tabular}{|c|c|c|c|c|}
\hline Parameters & $\begin{array}{l}\text { Never } \\
(n=44)\end{array}$ & $\begin{array}{c}\text { Light } \\
(n=52)\end{array}$ & $\begin{array}{l}\text { Heavy } \\
(n=48)\end{array}$ & \\
\hline Periodontal & $\%$ (SE) & $\%$ (SE) & $\%(\mathrm{SE})^{*}$ & $\mathrm{p}^{\mathrm{a}}$ \\
\hline Gingivitis & $34.2(1.5)$ & $41.6(2.7)$ & $37.4(3.4)$ & 0.214 \\
\hline Moderate periodontitis & $10.5(0.9)$ & $16.3(1.3)$ & $22.8(2.2)$ & 0.006 \\
\hline Severe periodontitis & $2.1(0.8)$ & $5.8(1.7)$ & $8.2(2.6)$ & 0.014 \\
\hline Bleeding on probing & $4.4(1.3)$ & $5.6(2.2)$ & $4.8(1.5)$ & 0.125 \\
\hline Sites with probing depth $>4 \mathrm{~mm}$ & $18.9(1.6)$ & $28.3(3.2)$ & $35.7(3.8)$ & 0.015 \\
\hline Periodontal & Mean (SE) & Mean (SE) & Mean (SE) & $\mathrm{p}^{\mathrm{b}}$ \\
\hline Maximum CAL (mm) & $3.2(0.5)$ & $6.4(0.7)$ & $7.9(0.6)$ & 0.000 \\
\hline Mean CAL (mm) & $2.9(0.5)$ & $4.1(1.2)$ & $5.3(0.9)$ & 0.001 \\
\hline Maximum PPD (mm) & $3.8(0.2)$ & $7.0(0.4)$ & $8.2(0.3)$ & 0.003 \\
\hline Mean PPD (mm) & $3.3(0.1)$ & $4.8(0.3)$ & $5.7(0.4)$ & 0.018 \\
\hline Mean number of teeth & $28(1.3)$ & $26(0.8)$ & $23(0.3)$ & 0.087 \\
\hline Potentially malignant lesions & $\%(\mathrm{SE})$ & $\%(\mathrm{SE})$ & $\%(\mathrm{SE})$ & $\mathrm{p}^{\mathrm{c}}$ \\
\hline Nicotinic stomatitis & $0(0.0)$ & $3.8(1.1)$ & $12.5(1.3)$ & 0.000 \\
\hline Leukoplakia & $2.3(0.3)$ & $1.9(0.2)$ & $6.3(0.7)$ & 0.001 \\
\hline Erythroplakia & $0(0.0)$ & $0(0.0)$ & $2.1(0.2)$ & 0.143 \\
\hline Lichen planus & $0(0.0)$ & $0(0.0)$ & $2.1(0.2)$ & 0.287 \\
\hline Non-healing ulcer & $0(0.0)$ & $0(0.0)$ & $4.3(0.8)$ & 0.026 \\
\hline Indeterminate & $0(0.0)$ & $3.8(0.9)$ & $6.3(1.2)$ & 0.012 \\
\hline
\end{tabular}

* SE: standard error of mean. CAL: clinical attachment loss. PPD: probing pocket depth. a p-value based on chi-squared test. b p-value based on ANOVA test. c p-value based on Fisher's exact test.

Table 3. Association between sociodemographic variables and oral-health-related quality of life (\% with high impacts) $(\mathrm{N}=150)$

\begin{tabular}{|c|c|c|c|c|c|c|}
\hline Characteristics & Pain & Discomfort & Speech & Diet & Embarrassment & $\begin{array}{c}\text { Self- } \\
\text { consciousness* }\end{array}$ \\
\hline Total & 11.5 & 22.8 & 18.5 & 16.7 & 15.3 & 24.6 \\
\hline \multicolumn{7}{|l|}{ Age (years) } \\
\hline $18-29$ & 2.0 & 3.5 & 4.5 & 3.8 & 2.0 & 4.3 \\
\hline $30-49$ & 6.1 & 11.3 & 6.8 & 6.2 & 8.2 & 11.1 \\
\hline$\geq 50$ & 3.3 & 8.0 & 7.2 & 6.7 & 5.1 & 9.2 \\
\hline \multicolumn{7}{|l|}{ Income $(\mathrm{NGN})^{* *}$} \\
\hline$<20000$ & 2.9 & 6.1 & 3.1 & 4.5 & 4.2 & 5.3 \\
\hline $20000-50000$ & 3.2 & 5.8 & 6.0 & 5.1 & 4.7 & 7.5 \\
\hline 51000-100000 & 2.3 & 3.5 & 2.6 & 2.3 & 2.6 & 3.2 \\
\hline$>100000$ & 0.6 & 1.2 & 2.5 & 1.3 & 0.8 & 3.0 \\
\hline Chose not to answer & 2.5 & 6.2 & 4.3 & 3.5 & 3.0 & 6.6 \\
\hline \multicolumn{7}{|l|}{ Education } \\
\hline $\begin{array}{l}\text { High school education or } \\
\text { less }\end{array}$ & 3.5 & 9.4 & 6.8 & 5.8 & 5.0 & 9.4 \\
\hline $\begin{array}{l}\text { Post high school diploma/ } \\
\text { certificate }\end{array}$ & 4.6 & 8.9 & 7.6 & 6.1 & 6.0 & 9.8 \\
\hline University degree & 3.4 & 4.5 & 4.1 & 4.8 & 4.3 & 5.4 \\
\hline
\end{tabular}


Table 3. Continued

\begin{tabular}{|c|c|c|c|c|c|c|}
\hline Characteristics & Pain & Discomfort & Speech & Diet & Embarrassment & $\begin{array}{c}\text { Self- } \\
\text { consciousness* }\end{array}$ \\
\hline \multicolumn{7}{|l|}{$\begin{array}{l}\text { Number of household } \\
\text { members }\end{array}$} \\
\hline $1-3$ & 2.0 & 4.6 & 2.4 & 4.1 & 3.6 & 4.6 \\
\hline $3-6$ & 3.7 & 7.2 & 6.3 & 5.5 & 5.0 & 7.5 \\
\hline$>6$ & 5.8 & 11.0 & 9.8 & 7.1 & 6.7 & 12.5 \\
\hline \multicolumn{7}{|l|}{ Payment for healthcare } \\
\hline Some form of insurance & 3.8 & 7.5 & 7.4 & 7.5 & 6.0 & 8.6 \\
\hline Out of pocket & 7.7 & 15.3 & 11.1 & 9.2 & 9.3 & 16.0 \\
\hline \multicolumn{7}{|l|}{ Smoking status } \\
\hline Never & 1.1 & 2.6 & 1.0 & 1.3 & 1.1 & 2.9 \\
\hline Stopped & 2.2 & 4.4 & 2.1 & 2.5 & 2.4 & 3.7 \\
\hline Light & 3.7 & 7.0 & 7.0 & 5.2 & 4.5 & 7.9 \\
\hline Heavy & 4.5 & 9.8 & 8.4 & 6.7 & 7.3 & 10.1 \\
\hline \multicolumn{7}{|l|}{ Alcohol drinking } \\
\hline Never & 2.4 & 3.0 & 1.6 & 1.9 & 1.4 & 2.5 \\
\hline Stopped & 2.6 & 5.1 & 2.5 & 3.2 & 2.5 & 5.0 \\
\hline Light & 2.9 & 6.4 & 6.8 & 5.4 & 4.9 & 7.2 \\
\hline Heavy & 3.6 & 8.3 & 7.6 & 6.2 & 6.5 & 9.9 \\
\hline \multicolumn{7}{|l|}{ Kola nut consumption } \\
\hline Never & 2.7 & 5.0 & 4.3 & 3.5 & 3.3 & 4.0 \\
\hline Occasional & 3.3 & 8.2 & 6.1 & 6.0 & 5.1 & 9.7 \\
\hline Daily & 5.5 & 9.6 & 8.1 & 7.2 & 6.9 & 10.9 \\
\hline
\end{tabular}

*Only 6 subdomains that were significant are included in the Table. ${ }^{* *}$ NGN: 361 Nigerian Naira about 1 US\$ in 2019.

In the multivariable logistic regression model, after controlling for alcohol consumption, kola nut chewing and other sociodemographic covariates, heavy cigarette smoking was a significant predictor of potentially malignant lesions (OR=1.89; 95\% CI: 1.33-3.27), severe periodontitis (OR=3.12; 95\% CI : 2.28-5.17) and severe OHRQoL impacts
(OR=2.35; 95\% CI: 1.42-4.54). For individual OHRQoL subdomains, Pain 3.03 (95\% CI: 1.77-4.21), Discomfort 2.89 (95\% CI: 2.32-4.17), Speech 3.02 (95\% CI: 2.32-4.13), Diet 2.77 [95\% CI: 1.87-4.28), Embarrassment 1.97 (95\% CI: 1.65-3.14) and Self-consciousness 2.34 (95\% CI: 1.93-3.48) were significantly associated with heavy smoking (Table 4).

Table 4. Odds ratios from the logistic regression model between significant predictor variables in the bivariate analysis and outcome variables

\begin{tabular}{|c|c|c|c|}
\hline Variables & $\mathrm{AOR}^{\mathrm{a}}$ & $95 \% \mathrm{CI}$ & $\mathbf{p}$ \\
\hline \multicolumn{4}{|c|}{ Potentially malignant lesions } \\
\hline Never smoker & 1 & & \\
\hline Light smoker & 1.28 & $0.58-1.79$ & 0.032 \\
\hline Heavy smoker & 1.89 & $1.33-3.27$ & 0.000 \\
\hline \multicolumn{4}{|c|}{ Severe periodontitis } \\
\hline Never smoker & 1 & & \\
\hline Light smoker & 2.05 & $0.99-3.14$ & 0.013 \\
\hline Heavy smoker & 3.12 & $2.28-5.17$ & 0.000 \\
\hline \multicolumn{4}{|c|}{ OHRQoL (severe impact) } \\
\hline Never smoker & 1 & & \\
\hline Light smoker & 1.44 & $0.64-2.47$ & 0.029 \\
\hline Heavy smoker & 2.35 & $1.42-4.54$ & 0.001 \\
\hline
\end{tabular}


Table 4. Continued

\begin{tabular}{l|cccccc} 
Variables & Pain & Discomfort & Speech & Diet & $\begin{array}{c}\text { Self- } \\
\text { Embarrassment } \\
\text { consciousness* }\end{array}$ \\
Never smoker & 1 & 1 & 1 & 1 & 1 & 1 \\
Light smoker & 1.64 & 1.38 & 1.33 & 1.20 & 1.37 & 1.68 \\
& $(0.98-2.24)$ & $(1.02-1.96)$ & $(0.86-2.05)$ & $(0.77-1.55)$ & $(1.14-1.92)$ & $(1.27-1.84)$ \\
Heavy smoker & 3.03 & 2.89 & 3.02 & 2.77 & 1.97 & 2.34 \\
& $(1.77-4.21)$ & $(2.32-4.17)$ & $(2.32-4.13)$ & $(1.87-4.28)$ & $(1.65-3.14)$ & $(1.93-3.48)$
\end{tabular}

a AOR: adjusted odds ratio, adjusted for alcohol consumption, kola nut use, and sociodemographic covariates. CI: confidence interval. OHRQoL: oral-health-related quality of life. * Only 6 subdomains that were significant are included in the Table.

\section{DISCUSSION}

This study investigated the association between the deleterious social habits of a cohort of bus drivers and their oral health status as well as their oral-health-related quality of life. Previous researchers have reported high levels of health-related events among bus drivers including cardiovascular disease, musculoskeletal complaints, psychosomatic disorders, chronic fatigue, and extreme stress ${ }^{27}$. They also have increased susceptibility to sickness absenteeism and disability than other occupational groups ${ }^{28}$.

Our sample of 150 male respondents comprised mainly those aged 30-49 years who had high school level education or less. Unavoidably, high-risk groups mostly belong to lower socioeconomic groups, who least attend clinics or utilize other health services, thus limiting an opportunity for visual examination by a clinician ${ }^{29}$. There was a high prevalence for ever use of cigarettes, alcohol and kola nut among study participants. The high prevalence of smoking among these drivers indicates that this cohort is particularly vulnerable to initiating and continuing a smoking habit. Influences such as peer pressure, relative availability, ease of access to and affordability of cigarettes, as well as the high level of stress associated with their occupation and the perceived need for use of stimulants, may contribute to the high prevalence of smoking among these drivers ${ }^{30}$. Commercial bus drivers are thus an important high-risk group for tobacco control initiatives in Nigeria.

A high proportion also drink alcohol and consume kola nuts. There has been a rapid increase in alcohol consumption across all age groups in Nigeria ${ }^{31}$. It is common to see alcohol sold by hawkers or in kiosks in small sachets and bottles, within and around motor parks, without any opposition due to weak regulatory overseeing. The carcinogenic effect of tannins from kola nut has also been documented when it is taken in large quantities, frequently, and for a long time $\mathrm{e}^{32}$. A review of literature shows that numerous biological, psychological, social and familial factors predispose bus drivers to substance abuse $\mathrm{e}^{33}$.We observed significant associations between income, educational attainment, smoking, alcohol consumption, kola nut consumption, and age group. Respondents aged 30-49 years, who represent the most productive age group, were significantly more likely to be heavy smokers, heavy alcohol drinkers, and daily kola nut consumers. Choi et al. ${ }^{34}$ hypothesized that workload and work resources based on specific working conditions such as prolonged driving, irregular shifts, conflicts with passengers, extended sedentary work, ergonomic hazards within the context of low wages, age, male gender, low educational attainment and poor health behaviors are fundamental in understanding drivers' work-stress-related health outcomes.

The prevalence of gingivitis was insignificantly higher among light smokers while the prevalence of moderate/ severe periodontitis was significantly higher among heavy smokers. Studies have confirmed that gingival inflammatory response is altered by smoking, which has anti-hemorrhagic and anti-inflammatory effects, essentially inhibiting the cardinal signs of redness, bleeding, and edema ${ }^{35}$. Heavy smokers, however, had significantly higher percentage of periodontal sites with probing depth and clinical attachment loss $>4 \mathrm{~mm}$. Descriptive and analytical studies show a strong epidemiologic association between smoking and an increased risk of periodontitis in smokers. In a large study of 1361 subjects in the US, smokers had a greater risk of experiencing severe bone loss than non-smokers, with odds ratios ranging from 3.25 to 7.28 for light and heavy smokers, respectively ${ }^{36}$.

Nicotinic stomatitis and leukoplakia were similarly significantly prevalent among heavy smokers while they also had more erythroplakia, lichen planus, non-healing ulcers, and indeterminate lesions. Regardless of the form of usage, all tobacco products contain hazardous chemicals with over 4000 known constituents. These include carbon monoxide, hydrogen cyanide, reactive oxidizing radicals, a high number of carcinogens, and of course nicotine, the main psychoactive and addictive molecule ${ }^{37}$. Alcohol has been found to increase the risk of premalignant lesions in the presence of tobacco16. Data from literature show that the malignant potential of leukoplakia, oral lichen planus and oral submucous fibrosis is $3.5 \%$, with a reported ${ }^{38}$ range of $0.13-34 \%$.

The development of oropharyngeal cancer is often subtle and asymptomatic. Invasive oral squamous cell carcinoma is frequently heralded by clinically identifiable premalignant changes of the oral mucosa. Careful monitoring of these 
lesions by an experienced specialist is highly recommended to identify any malignant changes in the early stages to reduce the cancer burden. Consequently, it is imperative for the clinician to maintain a high index of suspicion, especially in high risk groups like bus drivers who abuse tobacco and alcohol. Usually, when the premalignant lesions are not identified and late-stage symptoms such as bleeding, tooth mobility, ill-fitting dentures, dysphagia and odynophagia develop, the morbidity and mortality are usually more severe ${ }^{14}$. Secondary prevention through screening and prompt referral is thus advocated in this high-risk cohort.

We correspondingly observed more adverse oral impacts among heavy smokers, heavy alcohol drinkers and daily kola nut consumers, especially in the domains of pain in the mouth, discomfort with social interaction, difficulty with speaking, chewing difficulties, social embarrassment, and self-consciousness. There was a successive gradient risk for oral impact, with heavy smokers and heavy alcohol drinkers having the highest likelihood of oral impacts, followed by the moderate smokers and drinkers, compared to those who had never smoked or drank. These associations persisted in our multivariate regression model. Maida et al. ${ }^{20}$ observed worse OHRQoL among current smokers while Åstrøm et al. ${ }^{21}$ observed a correlation between the duration of smoking and OHRQoL. Smoking and alcohol consumption are associated with depression ${ }^{39}$, esteem issues, tooth loss, stained teeth, oral malodor, and social exclusion, which are correlated with quality of life ${ }^{18,19}$. Due to weak implementations of the recommendations of MPOWER, resulting in cheap cigarettes that are widely available and freely smoked in car parks, bus drivers who are largely of low socioeconomic status with poor health seeking behavior, represent a high-risk group that should receive adequate attention for cessation services.

\section{Limitations}

Some limitations should be considered when interpreting our results. First, the descriptive study design limits our ability to make causal inferences from the associations that we observed. Second, the smoking status and other deleterious habits of the respondents were determined by self-report and not verified by exhaled carbon monoxide or urinary cotinine levels, giving the possibility of bias in reported prevalence values. Thirdly, even though we stringently utilized the WHO criteria for determining premalignant lesions, as obtained in clinical practice, we were unable to obtain biopsy samples for confirmatory histopathology due to the limited consent we were given by the participating union of drivers (NURTW). Within the context of these limitations, our study provides the first of such baseline community data in Nigeria.

\section{CONCLUSIONS}

This study shows that smoking and alcohol consumption have significant independent associations with periodontal disease, premalignant lesions, and oral-health-related quality of life, with the worst impacts recorded in heavy smokers and drinkers. It highlights the role of tobacco and alcohol as modifiable risk factors for periodontal disease and potentially malignant lesions that can impact negatively on oral-health-related quality of life. Bus drivers in Lagos State, Nigeria, are an important target group in controlling tobacco and alcohol use in Nigeria and should receive adequate attention for oral health promotion, regular screening, and other preventive initiatives.

\section{REFERENCES}

1. Landsbergis PA, Grzywacz JG, LaMontagne AD. Work organization, job insecurity, and occupational health disparities. Am J Ind Med. 2014;57(5):495-515. doi:10.1002/ajim.22126

2. Gay Anderson D, Riley P. Determining standards of care for substance abuse and alcohol use in long-haul truck drivers. Nurs Clin North Am. 2008;43(3):357-365. doi:10.1016/j.cnur.2008.04.003

3. Zhang X, Chow EP, Wilson DP, Sun X, Zhao R, Zhang J, Jing J, Zhang L. Prevalence of HIV and syphilis infections among long-distance truck drivers in China: A data synthesis and meta-analysis. Int J Infect Dis. 2013;17(1):e2-e7. doi:10.1016/j.ijid.2012.07.018

4. Singh RK, Joshi HS. Sexual behavior among truck drivers. Indian J Public Health. 2012;56(1):53-56. doi:10.4103/0019-557x.96976

5. Nascimento EC, Nascimento E, Silva Jde P. Alcohol and amphetamines use among long-distance truck drivers. Rev Saude Publica. 2007;41(2):290-293. doi:10.1590/S0034-89102007000200017

6. Labat L, Fontaine B, Delzenne C, et al. Prevalence of psychoactive substances in truck drivers in the Nord-Pas-deCalais region (France). Forensic Sci Int. 2008;174(2-3):90-94. doi:10.1016/j.forsciint.2007.03.004

7. Ebrahimi MH, Delvarianzadeh M, Saadat S. Prevalence of metabolic syndrome among Iranian occupational drivers. Diabetes Metab Syndr. 2016;10(1):S46-S51. doi:10.1016/j.dsx.2015.09.011

8. Saini GK, Gupta ND, Prabhat KC. Drug addiction and periodontal diseases. J Indian Soc Periodontol. 2013;17(5):587-591. doi:10.4103/0972-124x.119277

9. Yanagisawa T, Ueno M, Shinada K, Ohara S, Wright FA, Kawaguchi Y. Relationship of smoking and smoking cessation with oral health status in Japanese men. J Periodontal Res. 2019;45(2):277-283. doi:10.1111/j.1600-0765.2009.01233.x

10. Leung WK Ng DK, Jin L, Corbet EF. Tooth loss in treated periodontitis patients responsible for their supportive care arrangements. J Clin Periodontol. 2006;33(4):265-575. doi:10.1308/135576106778529044

11. da Silva ACF, Luiz RR, Leão AT. The relationship between alcohol dependence and periodontal disease. J Periodontol. 2008;79(6):993-998. doi:10.1902/jop.2008.070525

12. Marr JJ, Spilberg I. A mechanism for decreased resistance to infection by gram-negative organisms during acute alcoholic intoxication. J Lab Clin Med. 1975;86(2):253-258. 
PMID:807663.

13. Khocht A, Janal M, Schleifer S, Keller S. The influence of gingival margin recession on loss of clinical attachment in alcoholdependent patients without medical disorders. J Periodontol. 2003;74(4):485-493. doi:10.1902/jop.2003.74.4.485

14. Neville BW, Day TA. Oral cancer and pre-cancerous lesions. CA Cancer J Clin 2002;52(4):195-215. doi:10.3322/canjclin.52.4.195

15. Mello FW, Melo G, Pasetto JJ, Silva CAB, Warnakulasuriya $\mathrm{S}$, Rivero ERC. The synergistic effect of tobacco and alcohol consumption on oral squamous cell carcinoma: a systematic review and meta-analysis. Clin Oral Investig. 2019;23(7):2849-2859. doi:10.1007/s00784-019-02958-1

16. Melrose RJ. Premalignant oral mucosal diseases. J Calif Dent Assoc. 2001;29:593-600. PMID:11577670.

17. Hashibe M, Sankaranarayanan R, Thomas G, et al. Body mass index, tobacco chewing, alcohol drinking and the risk of oral submucous fibrosis in Kerala, India. Cancer Causes Control. 2002;13(1):55-64. doi:10.1023/a:1013991025848

18. Hashibe M, Mathew B, Kuruvilla B, et al. Chewing tobacco, alcohol, and the risk of erythroplakia. Cancer Epidemiol Biomarkers Prev. 2000;9(7):639-645. PMID:10919731.

19. Benedetti G, Campus G, Strohmenger L, Lingström P. Tobacco and dental caries: a systematic review. Acta Odontol Scand. 2013;71(3-4):363-371. doi:10.3109/00016357.2012.734409

20. Millar W J, Locker D. Smoking and oral health status. J Can Dent Assoc. 2007;73(2):155. PMID:17355806.

21. Maida C A, Marcus M, Spolsky V W, Wang Y, Liu H. Sociobehavioral predictors of self-reported oral healthrelated quality of life. Qual Life Res. 2013;22(3):559-566. doi:10.1007/s11136-012-0173-z

22. Åstrøm AN, Ekback G, Ordell S, Unell L. Social inequality in oral health-related quality of life, OHRQoL, at early older age: evidence from a prospective cohort study. Acta Odontol Scand. 2011;69(6):334-342. doi:10.3109/00016357.2011.568965

23. Lagos State Ministry of Science and Technology, Lagos State Government. About Lagos. 2018. https://lagosstate.gov.ng/ about-lagos/. Accessed October 8, 2019.

24. Sreedevi M, Ramesh A, Dwarakanath C. Periodontal status in smokers and nonsmokers: a clinical, microbiological, and histopathological study. Int J Dent. 2012;2012:1-10. doi:10.1155/2012/571590

25. Slade GD. Derivation and validation of a short-form oral health impact profile. Community Dent Oral Epidemiol. 1997;25(4):284-290. doi:10.1111/j.1600-0528.1997.tb00941.x

26. Kramer IR, Pindborg JJ, Bezroukov V, Infirri JS. Guide to epidemiology and diagnosis of oral mucosal diseases and conditions. World Health Organization. Community Dent Oral Epidemiol. 1980;8(1):1-26.

CONFLICTS OF INTEREST

The authors have completed and submitted the ICMJE Form for Disclosure of Potential Conflicts of Interest and none was reported.

FUNDING

There was no source of funding for this research. doi:10.1111/j.1600-0528.1980.tb01249.x

27. Tse JLM, Flin R, Mearns K. Bus driver well-being review: 50 years of research. Transportation Research Part F: Traffic Psychology and Behaviour. 2006;9(2):89-114. doi:10.1016/j.trf.2005.10.002

28. Benavides FG, Benach J, Mira M, Sáez M, Barceló A. Occupational categories and sickness absence certified as attributable to common diseases. Eur J Public Health. 2003;13(1):51-55. doi:10.1093/eurpub/13.1.51

29. Jornet PL, Garcia FJ, Berdugo ML, Perez FP, Lopez AP. Mouth self-examination in a population at risk of oral cancer. Aust Dent J. 2015;60(1):59-64. doi:10.1111/adj.12274

30. Aniebue PN, Okonkwo KOB. Prevalence of psychoactive drug use by taxi drivers in Nigeria. J College Med. 2008;13(3):4852. doi:10.3126/jcmsn.v13i3.18403

31. Lasebikan VO, Gureje 0. Lifetime and 7-day alcohol consumption in the elderly, prevalence and correlates: Reports from the Ibadan Study of Aging. Afr J Med Med Sci. 2015;44(1):33-41. PMID:26548114.

32. Young LA, Young LG, Klein MM, Klein DM, Beyer D. Recreational drugs. New York, NY: Macmillan Pub Co; 1985.

33. Galanter M. Innovations: alcohol \& drug abuse: spirituality in Alcoholics Anonymous: a valuable adjunct to psychiatric services. Psychiatr Serv. 2006;57(3):307-309. doi:10.1176/appi.ps.57.3.307

34. Choi B, Schnall P, Dobson M, Yang H, Baker D, Seo Y. A socioecological framework for research on work and obesity in diverse urban transit operators based on gender, race, and ethnicity. Annals of Occupational and Environmental Medicine. 2017;29(1):15. doi:10.1186/s40557-017-0171-2

35. Dietrich T, Bernimoulin J-P, Glynn R. The effect of cigarette smoking on gingival bleeding. J Periodontol. 2004;75(1):1622. doi:10.1902/jop.2004.75.1.16

36. Grossi SG, Genco RJ, Machtei EE, et al. Assessment of risk for periodontal disease: II: Risk indicators for alveolar bone loss. J Periodontol. 1995;66(1):23-29. doi:10.1902/jop.1995.66.1.23

37. Benowitz NL. Pharmacology of nicotine - addiction and therapeutics. Annu Rev Pharmacol Toxicol. 1996;36(1):597613. doi:10.1146/annurev.pa.36.040196.003121

38. Warnakulasuriya S, Ariyawardana A. Malignant transformation of oral leukoplakia: a systematic review of observational studies. J Oral Pathol Med. 2016;45(3):155166. doi:10.1111/jop.12339

39. Hämäläinen J, Kaprio J, Isometsä E, Heikkinen M, Poikolainen $\mathrm{K}$, Lindeman S, Aro S. Cigarette smoking, alcohol intoxication and major depressive episode in a representative population sample. J Epidemiol Community Health. 2001;55(8):573576. doi:10.1136/jech.55.8.573 